\title{
A interferência da carreira do magistério superior na qualidade de vida dos docentes da Universidade Federal de Viçosa-MG ${ }^{1}$
}

\section{The interference of the career of the superior magistrary in the quality of life of teachers of the Federal University of Viçosa-MG}

Michelle Barbosa Soares ${ }^{2}$ Simone Caldas Tavares Mafra ${ }^{3}$

\section{Resumo}

Qualidade de Vida (QV) é conceito abrangente, que envolve as dimensões consideradas importantes para o ser humano. O estudo objetivou verificar se a carreira dos docentes universitários da Universidade Federal de Viçosa interfere na QV dos professores. O estudo foi realizado na cidade de Viçosa, MG, tendo como unidade de pesquisa a Universidade Federal de Viçosa (UFV), campus Viçosa. Foram selecionados de forma aleatória 13 docentes universitários que estão lotados na UFV, campus Viçosa. Os resultados mostraram que os docentes se sentem realizados com seu trabalho, entretanto a sobrecarga de trabalho pode diminuir o seu tempo de lazer, diminuindo o tempo para a realização de atividade física, afetando as condições de saúde dos mesmos. Conclui-se que há sobrecarga de trabalho na carreira dos docentes universitários, e carência de conscientização dessa situação pelos gestores, para que haja modificação nas políticas de legitimação do atual sistema educacional.

Palavras-Chave: Professor; Bem-estar; Sobrecarga ocupacional.

\begin{abstract}
Quality of Life (QOL) is a comprehensive concept which involves the dimensions considered important for human. Thus, the present study aimed to verify if the career of university teaching staff from Universidade Federal de Viçosa interferes with QOL of professors. The study was conducted in Viçosa, $M G$, and the research unit was Universidade Federal de Viçosa (UFV), Viçosa campus. We selected randomly 13 university professors who are crowded at UFV, Viçosa campus. The results showed that teachers feel fulfilled with their work, but the work overload can reduce their leisure time, reducing the time to perform physical activity, affecting their health conditions. We conclude that college teachers are work overloaded and managers should be aware of this situation so that they can change the political legitimacy of the current educational system and its principles, especially the form of assessment of intellectual production.
\end{abstract}

Key-words: Teacher. Welfare. Occupational overload.

\footnotetext{
1 O presente trabalho foi realizado com apoio da Coordenação de Aperfeiçoamento de Pessoal de Nível Superior - Brasil (CAPES).

2 Doutoranda em Fisioterapia pela Universidade Federal de São Carlos (UFSCAR). Professora da Faculdade de Ciências Biológicas e da Saúde (FACISA - UNIVIÇOSA).E-mail: msmichellesoares@yahoo.com.br

${ }^{3}$ Doutora em Engenharia de Produção pela Universidade Federal de Santa Catarina. Professora do Programa de Pós-Graduação em Economia Doméstica da Universidade Federal de Viçosa. E-mail: sctmafra@ufv.br
} 


\section{INTRODUÇÃO}

Qualidade de Vida é conceito abrangente, que envolve as dimensões consideradas importantes para o ser humano, pois é definição individual e subjetiva, e dependerá da representação de cada sujeito a respeito da realidade social que o cerca (PEREIRA, 2006; SILVA, 1997). Comumente, é ainda utilizada como sendo a percepção do indivíduo em relação à vida, ao bem-estar físico e emocional, estritamente influenciada por fatores sociais, culturais, ambientais, éticos e pelo trabalho (PEREIRA, 2006). Está também diretamente relacionada com as expectativas pessoais e os projetos de vida.

Deste modo, entre os fatores que influenciam a QV está a atividade profissional, em virtude das transformações no mundo do trabalho, como mudanças na economia, na organização produtiva brasileira e na organização do trabalho. Além das políticas públicas atuais, que incentivam a competição, a desregulamentação da economia, a proposição do Estado mínimo, com a redução dos investimentos nas áreas de saúde, educação e moradia (HUÉ, 2012; LIMA, 2009), vem causando diversos males ao ambiente de trabalho.

Em meio a toda a desestruturação que se encontra a economia e, consequentemente, o universo do trabalho, destaca-se a carreira do docente universitário que também vem sofrendo as consequências da exploração e da competitividade em seu ambiente de trabalho. Uma vez que as especificidades do trabalho docente configuram ao professor, ao longo do tempo, sua identidade profissional, pois todo seu processo de interação, assimilação de conhecimento e socialização com a atuação profissional fazem com que ele se torne um professor delineado pelas suas ideias, ideais, interesses e ethos (TARDIF, 2000).

Além disso, o professor universitário tem se deparado com a precariedade dos recursos didáticos; com normas e procedimentos administrativos inadequados à universidade; as excessivas funções burocráticas atribuídas ao docente; as interrupções durante as aulas; as condições deficitárias_das instalações físicas; e a constante cobrança pela qualificação, pela competência que é avaliada, periodicamente, tanto institucionalmente, como por alunos e pela direção, e, externamente pelo Ministério da Educação - MEC - e, ainda, pela produção científica dos professores (PEREZ, 1992; FERREIRA, 2011; KOETZ, 2013). Todos esses fatores podem afetar o desempenho pessoal, profissional e a saúde dos docentes, levando-os a condição de estresse.

Diante do exposto, o presente estudo trouxe como objetivo verificar se o exercício da atividade de docente em carreira do magistério superior de uma instituição pública interfere na qualidade de vida dos docentes. 


\section{FUNDAMENTAÇÃO TEÓRICA}

\section{A carreira docente}

O surgimento da carreira de docente pode ter ocorrido na sociedade "greco-romana", onde encontram-se vestígios nos escritos antigos da época (SINGER, 1986). Na atualidade, a carreira de docente, na universidade, passa por crises que seguem a lógica da pós-modernidade (PEREIRA, 2006).

Esses docentes, que atuam nas instituições de ensino superior, enfrentam obstáculos para manterem seu tripé de atuação, ensino, pesquisa, extensão, que estão diretamente relacionados à produção e transferência dos conhecimentos produzidos na academia, repassados ao sistema de produção de bens e serviços (TAFFAREL, 1997; OLIVEIRA, 1997; DARIDO, 1998). Segundo Fernandes (1998), possuem também cinco particularidades que diferenciam este nível de atuação dos demais níveis de educação, que são: a formação intelectual longa, a aquisição de competência técnica e o princípio de especialização, a perspectiva da oferta de serviço relevante para o conjunto da coletividade, o controle pelos pares das formas de competência, o desenvolvimento de autonomia profissional.

Compreende-se, ainda, a prevalência de situações estressantes que prejudicam a saúde dos docentes e que interferem nos seus desempenhos pessoal e profissional, com manifestação de sintomas associados ao estresse como agitação e apatia (CONTAIFER et al., 2003; SILVA, 2006).

Dessa forma, recomenda-se que o homem recupere o seu papel social produtivo, deixando de ser alienado a toda esta realidade, conscientizando-se de sua importância como um ser que precisa de motivação, de satisfação plena, de ter autoestima e de ser útil (PEREIRA, 2006). Para isso, é necessário considerar a qualidade de vida dos docentes universitários como um conceito amplo que deverá englobar aspectos subjetivos (sentimentos, percepções, bemestar, grau de satisfação, relacionamentos interpessoais) e objetivos (lazer, saúde, salário, realização de atividade de carreira), estimulando a participação dos trabalhadores na solução de problemas e tomada de decisões, o que tenderá a aumentar a Qualidade de Vida dos docentes universitários. 


\section{Qualidade de Vida}

A Organização Mundial da Saúde (OMS) define qualidade de vida como a percepção do indivíduo de sua vida, no contexto da cultura e sistemas de valores nos quais ele vive e em relação aos seus objetivos, expectativas, padrões e preocupações (FLECK et al., 1999).

O termo qualidade de vida é abrangente, incluindo fatores relacionados à saúde, como os físicos, funcionais, emocionais e bem-estar mental. Assim, como aqueles não-relacionados, quais sejam trabalho, família, amigos e outros aspectos da vida. A qualidade de vida relacionada à saúde envolve vários domínios da vida do indivíduo, sendo os mais comumente estudados o psicológico, o social e o físico.

Para Nahas (1995), muitos são os fatores que influenciam a qualidade de vida de um indivíduo. Dentre os diferentes fatores ele destaca: condição de saúde, salário, moradia e aspectos subjetivos como humor, autoestima e autoimagem. Na realidade, engloba estilo de vida, hábitos cotidianos, reações frente às circunstâncias e ao ambiente, atividades, trabalho, descanso, socialização, relações pessoais, uso do tempo, vontades e desejos.

$\mathrm{Na}$ busca por qualidade de vida e realização profissional, as pessoas têm vivenciado pressões por resultados. Essas situações fazem com que as pessoas se tornem frágeis e se sintam divididas entre usufruir da vida pessoal, ou obter a realização profissional. E o organismo nessa situação acaba por reagir de forma negativa podendo gerar o estresse (BERNHOEFT, 1991).

Essas exigências da vida moderna, e no âmbito do trabalho, podem levar os indivíduos a, gradativamente, desenvolver algum tipo de distúrbio, uma vez que as atribuições diárias, a má alimentação, a falta de tempo para o lazer, o pouco tempo para o descanso e o sono, acabam resultando em má qualidade de vida e, consequentemente, em estresse (LIPP, 2002). Em parte isso tem ocorrido em virtude de a qualidade de vida do trabalhador não estar dentre as prioridades das organizações, uma vez que, ao invés de procurarem aumentar a capacidade das pessoas de ascenderem e realizarem conquistas, estão fazendo com que um maior número de trabalhadores sacrifique sua vida e pretensões pelo bem-estar das empresas (MASLACH; LEITER, 1999). 


\section{PROCEDIMENTOS METODOLÓGICOS}

\section{Caracterização da pesquisa}

A presente pesquisa teve como foco de estudo a verificação da QV dos docentes da Universidade Federal de Viçosa (UFV), através de pesquisa qualitativa.

\section{Local do estudo}

O estudo foi realizado na cidade de Viçosa, MG, tendo como unidade de pesquisa a Universidade Federal de Viçosa, campus Viçosa.

A UFV teve sua origem na Escola Superior de Agricultura e Veterinária (ESAV), fundada em 30 de março em 1922 e inaugurada em 28 de Agosto de 1926. Hoje, após 92 anos de existência, a instituição possui 45 cursos de graduação que se organizam nos seguintes Centros de Ciências: Ciências Agrárias (CCA), Ciências Biológicas e da Saúde (CCB), Ciências Exatas e Tecnológicas (CCE) e Ciências Humanas, Letras e Artes ( $\mathrm{CCH}$ ). Conta também com um total de 44 cursos de pós-graduação Strictu Sensu no campus Viçosa. A relevância desta instituição para o estudo proposto consiste no fato de ser a UFV referência nacional e internacional, no ensino e na pesquisa, e ser considerada uma das instituições brasileiras com índices mais elevados de qualificação do quadro de pessoal docente (mestrado e doutorado) (UFV, 2015).

\section{Definição da amostra e técnicas de coleta de dados}

Foram selecionados de forma aleatória treze docentes universitários que estão lotados na UFV, campus Viçosa. Realizou-se entrevistas semiestruturadas, com questões relacionadas à qualidade de vida e outras referentes à carreira docente.

A definição, para a escolha da quantidade de entrevistas a serem realizadas, foi a saturação dos dados. O fechamento amostral por saturação teórica é operacionalmente definido como a suspensão de inclusão de novos participantes quando os dados obtidos passam a apresentar, na avaliação do pesquisador, certa redundância ou repetição, não sendo considerado relevante persistir na coleta de dados (FONTANELLA et al., 2008)

A coleta de dados se iniciou com a apresentação e explicação sobre a pesquisa, para a aplicação do Termo de Consentimento Livre e Esclarecido, a todos os sujeitos participantes da 
pesquisa, para então dar seguimento à realização das entrevistas semiestruturadas com os docentes.

\section{Análise e interpretação dos dados}

Para apresentação dos dados das treze entrevistas com os docentes lotados na UFV, campus Viçosa, utilizou-se letras e números (D1, D2, D3 ... D13) para preservar suas identidades. Assim deu-se início à análise do conteúdo das falas transcritas e organizadas emergindo oito categorias para análise:

1. A percepção e o conceito dos docentes sobre QV

2. A relação entre o lazer e o trabalho

3. A prática de atividades física

4. Aspectos relacionados COM a saúde dos docentes universitários

5. Relações interpessoais no trabalho

6. Sobrecarga de trabalho

7. Realização no trabalho

8. Carreira e QV

Após a estruturação das categorias de análise, iniciou-se as interpretações dos significados captados e intuídos nas mensagens analisadas. Em sequência, foi realizada a interpretação das falas, pois a adequada análise de conteúdo não basta categorizar e descrever, mas também interpretar o conteúdo, conforme descrito por Miles e Huberman, (1994). As variáveis empíricas que emergem dos dados do texto e que são conceituadas de modo indutivo, quando cruzadas com as variáveis previamente construídas, acabam trazendo à entrevista e à análise de seu conteúdo maior clareza e sentido aos pressupostos estudados.

Ao final, buscou-se interpretar e discutir os resultados, apoiados pela literatura, se preocupando em responder às perguntas de pesquisa e cumprir os objetivos deste estudo. Além dos aspectos mencionados, buscou-se ampliar o conhecimento e as discussões sobre a problematização proposta.

Em todo o processo da pesquisa foram atendidos os princípios éticos dispostos na resolução № 466/2012 do Conselho Nacional de Saúde, tendo este trabalho sido autorizado pelo comitê de ética em pesquisa com seres humanos da Universidade Federal de Viçosa através do CAAE: 45243915.1 .0000 .5153 e parecer de número 1.116.358. 


\section{RESULTADOS E ANÁLISES}

\section{Tema 1:}

\section{A percepção e o conceito dos docentes sobre QV}

A definição de QV para os entrevistados apresenta diferentes significados, como é possível perceber nas falas a seguir:

Para mim, eu acho que qualidade de vida é você trabalhar, satisfeita com o seu trabalho e ter tempo para se dedicar a coisas que você gosta, seja lá o que for. Ficar com a família, ter o tempo para você fazer atividade física, lazer, se alimentar bem (D6).

Significa você... viver de uma maneira equilibrada e plena, por exemplo, com realização pessoal e profissional. Você ter (...) uma boa vida profissional e familiar, eu acho que isso que completa o ser humano (...) sentido de uma vida plena (D8).

Então, qualidade de vida é muito uma questão e equilíbrio. A gente ter um equilíbrio de ordem familiar, que você consiga levar isso numa boa, você consiga realizar suas atividades físicas pessoais, as coisas que você gosta de fazer. E de você conseguir um trabalho que também permita você cumprir o seu horário de maneira equilibrado. Então, assim, é você regular um pouco o tempo familiar, o tempo de trabalho e o tempo da sua intimidade, (...) das coisas que você gosta. Então, hoje o nosso ambiente de trabalho, ele contribui muito pouco para essa qualidade de vida (D3).

A partir das falas, pode-se evidenciar que o principal significado dado à qualidade de vida, pelos docentes, foi obter realização profissional, ter boas condições de saúde e lazer, conseguir encontrar o equilíbrio entre a realização e a dedicação da vida pessoal, do trabalho e a vida familiar.

Assim, o sentimento vivenciado pelos docentes a respeito da realização profissional plena, pode ser explicado por o trabalho humano ser considerado um dos aspectos centrais do modelo de organização social atual (ANDRADE, 2001).

Os docentes, ao associarem o conceito de qualidade de vida às condições necessárias para atendimento de suas necessidades, confirmam a validade do conceito norteador da pesquisa, propostos por Nahas (1995), qual seja, ter qualidade de vida engloba vários fatores que influenciam a vida de um indivíduo, como estilo de vida, hábitos cotidianos, reações frente às circunstâncias e ao ambiente, atividades, trabalho, descanso, socialização, relações pessoais, uso do tempo, vontades e desejos.

A partir do conceito da QV, foram emergindo as categorias de análise deste estudo, pela percepção dos docentes universitários sobre a relação e a influência de sua carreira sobre o significado de QV. 


\title{
Tema 2:
}

\section{$\underline{\text { A relação entre o lazer e o trabalho }}$}

Para os docentes que participaram da pesquisa, o lazer é tido como o momento de descanso, horário que não desejam se expressar sobre trabalho. De tal modo que a produção não faz parte desse momento, pois se trata de o período no qual seu preenchimento se relaciona com atividades que thes proporcionem prazer e bem-estar, bem como relaxamento, distração e entretenimento, como nos depoimentos a seguir:

[...] o lazer é o momento que eu saio do ambiente de trabalho, que eu posso me dedicar às coisas que eu gosto. Que eu posso, por exemplo, estar com a minha família, que eu posso me divertir com os meus filhos, posso brincar com eles. Esse é um momento de lazer. E que eu preciso investir mais neles assim, em momentos que nos revigoram para voltar ao trabalho (D3).

\begin{abstract}
Na verdade, para mim, com o meu trabalho no dia a dia e com o grau de estresse, ou de cansaço mental, você tem que pensar o tempo todo, estar desenvolvendo trabalhos vamos dizer assim - desgaste mental alto. Lazer, para mim, é quando eu faço uma atividade... uma atividade prazerosa, e que você vai ali e descansa. [...] O lazer, para mim, é qualquer atividade que descanse a minha mente. Mas as vezes, o trabalho interfere nesse momento (D8).
\end{abstract}

Lazer para mim, é eu estar com a cabeça livre. Estar com tempo livre para fazer algo que me dê prazer. Mas não tenho tido muito tempo para o lazer por conta do trabalho (D5).

Deste modo, o significado do lazer, para os docentes universitários, foi considerado como algo que proporcione prazer e envolvimento familiar e possui oposição ao trabalho, uma vez que deve proporcionar descanso, divertimento e descontração. Os professores compreenderam o lazer em ótica funcionalista, ele é um fim em si mesmo e uma possibilidade de desenvolvimento.

De acordo com Requixa (1977, p. 95 apud PINTO, 2008), "tratando o lazer dessa forma se busca a paz social e a manutenção da ordem, instrumentalizando o lazer como fator que ajuda a suportar a disciplina e as imposições obrigatórias da vida social, pela ocupação do tempo livre em atividades equilibradas, socialmente aceitas e moralmente corretas".

Nota-se situação preocupante nas falas quando os docentes expressam que a quantidade de tempo destinado à esfera do trabalho pode adentrar nos momentos de lazer, pois não consideram vivenciar o tempo dedicado ao lazer de forma plena e satisfatória. Nesse sentido, para refletir o tempo, tem-se que pensar sobre a lógica das cobranças do trabalho, das obrigações familiares e acadêmicas. Apesar de estarem inseridos em uma sociedade que traz consigo muitos constrangimentos relativos à apropriação do tempo, é preciso que o indivíduo possua ou crie a possibilidade de realizar escolhas em busca de atividades que thes 
proporcionem prazer, contribuindo, assim, para a diminuição do cansaço mental e, consequentemente, da diminuição do estresse ocupacional (PINTO, 2008).

\title{
Tema 3:
}

\section{A prática de atividades física}

Quanto à prática de atividade física foi possível constatar que os docentes universitários consideram importante, como pode ser observado nas verbalizações:

\begin{abstract}
Não estou realizando nenhuma atividade física. Porque isso acabou sendo suprimido. [...] com a quantidade de trabalho, eu acabo me concentrando em fazer tudo que está sendo demandado na universidade. Espero que da próxima vez que a gente se encontre, eu talvez esteja fazendo alguma atividade física rotineira (D3).
\end{abstract}

Já. Joguei muito futebol, hoje não faço nenhuma atividade física, não tenho tempo (D1).

[...] Aí deixei o Pilates. [...] Pilates não deu tempo, eu estava fazendo. Eu não tenho saído daqui [...] eu não saio daqui antes das 19:00. Então eu... não que seja obrigado. Se eu quisesse, eu podia sair, mas eu ia deixar umas coisas para fazer, estressaria mais (D9).

Eu acho [...] quando a gente pratica exercício físico se sente melhor, é uma fonte de diminuição do estresse, se sente revigorado, e até aumenta a autoestima. Mas não tenho conseguido realizar (D4).

$\mathrm{Na}$ verdade, eu gosto de fazer atividade física, mas a minha sobrecarga de trabalho, às vezes, não deixa. Na prática, as pessoas vamos supor, falam assim "mas seu dia tem 24 horas?", tem, mas se você resolver dormir oito? Trabalha dez, uma hora para almoçar, e tem que visitar a família, complica (D8).

Portanto, é possível sugerir que a maioria dos participantes apresenta a necessidade de realizar atividades físicas e expõe também, a sensação de bem-estar com a prática dessas. Entretanto, mesmo considerando a atividade física essencial para diminuição do estresse e melhora da autoestima, verificou-se a dificuldade em manter um estilo de vida ativo pela sobrecarga de trabalho e pelo acúmulo de tarefas.

Assim, os fragmentos de verbalizações exemplificam claramente que as percepções baseiam-se nas experiências profissionais dos participantes. Em virtude da excessiva quantidade de trabalho, ocorre sobrecarga que prejudica suas vidas cotidianas, não conseguindo realizar um de seus anseios, que seria a prática de atividade física, e podem ficar expostos as consequências danosas do trabalho no âmbito físico, psíquico e social. A diminuição acentuada do nível de atividade física pode ser considerada uma das principais causas das doenças crônico degenerativas na sociedade atual. Estudos demonstram que as consequências do sedentarismo são negativas à saúde humana (FOX et al., 1991; SOUSA, 2017; PINHEIRO, 2018; ZAMAI, 2018), a atividade física influencia positivamente a promoção da saúde, (FOX, et al.,1991; BLAIR 
et al., 1998; PINHEIRO, 2018), pois combate a obesidade, a diabetes, a osteoporose, o câncer, a asma, e as doenças cardiovasculares, principais responsáveis pelas mortes nos países desenvolvidos e em desenvolvimento (BLAIR et al., 1998; PESCATELLO, 2001).

\section{Tema 4:}

\section{$\underline{\text { Aspectos relacionados a saúde dos docentes do magistério superior }}$}

Ao analisar as falas relacionadas à saúde dos docentes, nota-se algumas implicações entre o trabalho e a saúde, principalmente em virtude da grande sobrecarga de trabalho e do estresse ocupacional, podendo resultar em pouca qualidade de vida, possível problema dermatológico, problemas de visão, depressão, cansaço mental e alterações metabólicas. Possivelmente, o acúmulo de atividades destinadas ao professor interferiu significativamente nesse processo, como expressa as falas dos docentes:

Acho que tem momentos que realmente pelo estresse, pelo volume de atividade, pelo volume de reuniões, tem dia que você chega em casa já com dor de cabeça ou passa a semana inteira assim. Acho que outra coisa agora que está começando a despontar, é que como eu leio demais, é no computador, livro, problema de visão, então estou começando agora, marquei até um oftalmologista para amanhã cedo (D4).

Porque o meu estresse me levou a depressão. [...] Então eu tenho sintomas, eu somatizo muito, por exemplo uma dor de garganta. [...] o tempo todo estou prestando atenção no que está me tirando o sono. Outra coisa é que eu acordo muito ansiosa, às vezes (D5).

[...] Estava me dando umas manchas vermelhas - sabe? - aí falei "que negócio estranho", aí eu fui na dermatologista e ela falou: "Isso é estresse, é como se o tecido fosse morrendo, porque alto grau de estresse no organismo", aí ela falou assim "você toma remédio, um complexo vitamínico, faz exercício físico para equilibrar os [...] radicais livres" e tal. Aí, eu fiz um check-up de exame de sangue, estava dando um pouquinho de [...] triglicérides, ela falou: "Mas isso é falta de atividade, a tua alimentação é relativamente boa, é tipo um sinal de que tem alguma coisa começando a desandar. Eu [...] falei assim "vou sair depois do trabalho e fazer atividade física, mas é impossível (D8).

Segundo Minayo (1992), milhões de pessoas são acometidos, anualmente, por várias enfermidades no mundo. As causas destes acometimentos estão vinculadas ao modo de produção econômica e ao estilo de vida atual, decorrente tanto do excesso de trabalho, quanto da falta de tempo para a prática do lazer e das atividades físicas das pessoas inseridas nesse modelo.

Porém, o conceito de saúde não se restringe apenas à ausência de doença ou enfermidade. O processo saúde-doença tem sido analisado, considerando a qualidade de vida e seus aspectos ambientais, culturais, econômicos e existenciais, que envolvem as pessoas em seus diversificados processos de interação como indivíduo particular e coletivo (SILVERIO, 2010). O que explica o fato 
de os professores almejarem ter mais tempo para cuidar da própria saúde, praticar alguma atividade física, ter tempo para si, aproveitar momentos com a família e ter período dedicado ao lazer, mas não apresentam essa determinação, por não existir outra opção a não ser trabalhar. Os professores estão sujeitos a aceitar as condições estabelecidas pelo trabalho (REIS, 2013).

\section{Tema 5:}

\section{$\underline{\text { Relações interpessoais no trabalho }}$}

A análise dos depoimentos com relação aos pares revelou a complexidade do relacionamento interpessoal entre os docentes, como sentimentos de competitividade, posição ideológica contrárias, egocentrismo, difamação, vaidade, além do sistema de publicação que presa a quantidade e não a qualidade da produção intelectual, de tal modo que causa sobrecarga de trabalho, que implica diretamente no convívio social no trabalho dos docentes, como pode se visualizar nas falas que seguem:

Eu fico impressionado com [...] fofoca. No meio universitário, como tem fofoca. Isso não é papel de pesquisador. [...] Ai você vê as confusões que as pessoas causam, todo departamento tem (D9).

[...] muitos professores já chegaram chorando porque um outro professor discutiu com ele e falou que ele não sabe nada e coisa desse sentido, por posição ideológica divergente, então acho que para alguns talvez [...] as rixas ideológicas que têm no departamento é um problema muito grande. E como existe uma vaidade muito grande para cargo administrativo, para publicação e por aí vai, devido ao sistema de pontuação e ranqueamento de produtividade, essa vaidade acaba mexendo muito com os egos dentro do departamento, atrapalha o processo de interação (D4).

[...] assim, se você joga que a sua realização profissional está na pós-graduação. Então, você tem uma faca em cima da sua cabeça, ou no seu peito, você tem que publicar. E aí, como é que você faz com ensino, com reunião, com parte administrativa? Você começa a sair dessas coisas. Mas o outro também não quer. Aí, que começa a gerar as tensões, entendeu. Ninguém quer ser envolver com isso, nem com aquilo. Porque cada um tem que cuidar dessa questão aí. E aí, gera os atritos pessoais, geram os problemas, gera as discussões, gera tudo isso aí (D10).

Sobre os relacionamentos sociais no ambiente de trabalho, foi possível verificar percepções que não consideram o ambiente universitário propício à formação e manutenção de relações interpessoais, por causa das interferências significativas de diversas ordens, como a competitividade, as diferenças teóricas e ideológicas, e a sobrecarga de trabalho, típica da carreira do docente. Deste modo, é possível analisar que o ambiente universitário dificulta a formação e a manutenção de relacionamentos sociais, pois está cada vez mais impregnado pela lógica da competição e da exploração dos sujeitos, típicas do modelo de produção de bens e serviços, que acaba orientando o modelo de produção de conhecimento (SILVA, 2006). 
A competitividade exacerbada, segundo alguns dos entrevistados, causa dano às questões éticas, pois o produtivismo ultrapassa os aspectos essenciais à condição humana, independentemente da condição ocupacional dos indivíduos, como solidariedade, coletividade, dignidade, como pode ser observado na fala abaixo:

[...] Aí tem professor, por exemplo, que [...] pega o projeto do estudante, ele manda para agência de financiamento como se fosse o projeto que ele escreveu para conseguir bolsa de pesquisa para ele próprio, aí outro professor descobre essa situação e acaba, sei lá, difamando o outro professor. E cria um conflito, um ambiente ruim (D4).

Os professores da pós-graduação, eles formam um grupo, como se fosse assim, uma elite assim, sabe. Então, com esse argumento de que eles precisam apresentar produção, aí eles já começam a repassar para os outros professores que não são da pós-graduação, certos encargos. [...] Na universidade, por isso que eu falo, talvez seja um dos principais motivos seja esse, quer dizer, a produtividade individual de cada um é analisada, sem estar relacionada com a produtividade do todo. Então, faz com que cada um se feche. E grupos também se fechem. Grupos de pesquisa. E aí, aí gera todo o problema. Eu acho que é um dos principais motivos de ter esse ambiente ruim dentro da universidade. Em todas as universidades, você vê que é em todas as universidades (D10).

Portanto, percebe-se que, com o tempo, estas relações tendem a se tornar frágeis e o apoio necessário, em diferentes momentos, pode não ser o esperado. Estes laços são importantes para a construção de um apoio, pois, de acordo com Durkheim (1978), o convívio social é fonte de solidariedade e de empatia entre os pares.

A respeito das competências emocionais relacionadas à esfera do trabalho, Silveira (2006) averiguou as dificuldades para se exercer e aprender sobre desenvolvimento emocional. As ações, ligadas ao emocional, podem se referir às dificuldades de relacionamento interpessoal, que representam a capacidade de interação com as pessoas; aos problemas na estrutura emocional, que é a capacidade para enfrentar o dia a dia, com bons e maus momentos; às condições de suportar pressões; e às dificuldades em receber críticas de colegas, chefes e família. Coloca ainda como problema: as críticas das pessoas de seu convívio, a capacidade para reagir às frustrações e o saber respeitar o limite do outro.

De acordo com Ulrich (2005), as percepções de professores universitários sobre as relações interprofissionais possibilitariam verificar o quanto os professores compreendem as formas de relacionamento interpessoal como possíveis determinantes de desgaste físico e psicológico. 


\section{Tema 6:}

\section{Sobrecarga de trabalho}

Com relação ao excesso de trabalho dos docentes universitários, pode-se identificar pelas verbalizações dos docentes, sobrecarga de tarefas, ultrapassando os limites da instituição e a carga horária de 40 horas semanais, pois foi identificado a necessidade de realizar atividades ocupacionais no ambiente doméstico.

Trabalho até a hora de dormir. De vez em quando trabalho nos fins de semana (D6).

Tenho sido obrigado a levar trabalho para a casa, devido ao excesso de atividades (D9).

A carreira sobrecarrega muito. $O$ docente ele dificilmente desliga. Então é bastante estressante é muito exigido, em todos os aspectos. [...] Fim de semana sempre tem alguma coisinha que a gente faz. Só para você ter uma ideia, houve uma época aqui que eu lecionei 28-29 horas de aula por semana. E mantinha cinco orientados na pósgraduação, mestrado, doutorado, iniciação científica, vários na graduação, prestava assessoria para empresa (convênios firmados pelos departamentos e instituição, assessorias relacionadas ao ensino e estágio dos discentes). Isso nas quarenta horas quer dizer -, não era mais quarenta horas, usava muito o fim de semana (D1).

\section{Outras falas dos docentes universitários explicam a dinâmica de suas atividades}

ocupacionais e sua relação com a sobrecarga no trabalho.

Eu sinto que a [...] sobrecarga de trabalho é pelo [...] excesso de atividades que nós, docentes, temos que desenvolver. Nós orientamos aqui no meu departamento, por exemplo, os seis orientados de pós-graduação, mais dez estagiários, então, cada um conduzindo dois ou três experimentos, captação de recursos, projetos, que tem, que [...] eu sou como um gestor, eu tenho que captar recursos para mover toda essa equipe de trabalho que depende de mim em última instância. Então, há uma certa pressão, a instituição não dá nenhuma contrapartida, a instituição só dá o meu salário para eu dar aula, todas as outras atividades o profissional é que empreende e faz sozinho, se vira para tocar, os laboratórios, para o laboratório funcionar, tudo isso depende do professor. [...] uma das mais estressantes e mais trabalhosas que [...] despende muito tempo do profissional e não tem diretamente nenhum reconhecimento para a carreira, é a parte administrativa da instituição que é feita por nós, docentes. Por exemplo, [...] um departamento como o meu que é um departamento grande, tem várias comissões internas, comissões de ensino, de pesquisa, de extensão - certo? - às vezes, eu... por exemplo, sou presidente da comissão de pesquisa, então isso demanda tempo, avaliar relatórios, dar parecer em todos os projetos, isso não pontua nada na minha carreira, mas isso despende muito tempo. Tem outras atividades administrativas que nós, docentes, exercemos, e temos que exercer porque [...] elas fazem parte de fazer essa instituição funcionar (D8).

As publicações cada vez mais estão vinculadas às citações, então não dá para publicar, você tem que ser citado por alguém, assim, vai gerando uma pressão muito grande nisso. Então, eu acho que hoje, o professor ele depende de fazer esse currículo, está sujeito a um estresse maior [...] Tanto é que hoje a própria CAPES já abre discussões com relação à qualidade e quantidade de publicações. As pessoas são obrigadas a produzir. Mas tem 
pessoas lá que sofreram e isso é uma pressão muito grande para alguns [...] estavam lá sofrendo essa pressão de publicar, inclusive, no período que ele está fazendo doutorado (D5).

[...] às vezes, excede [...] corrige muita prova, então você corrige 250 provas de uma vez, você acaba tendo que fazer isso no fim de semana porque senão dá conta de fazer dia de semana. Chega época [...] a gente participa de uns três congressos aqui por ano, então assim, chega a época de congresso, são dois artigos para o congresso, mais ou menos, então você acaba tendo que ler, você também faz correção do artigo fim de semana, então não tem jeito, dependendo do período, a gente acaba levando bastante trabalho para casa.[...] E para fazer o doutorado aqui, eu não consegui liberação, então assim, eu tenho que fazer o doutorado trabalhando, é mais estressante ainda, aí é para acabar com o indivíduo mesmo, fazer o doutorado trabalhando é uma tristeza (D4).

É um trabalho [...] que sobrecarrega bastante o docente, assim. Porque ele não é só docente, ele acaba cumprindo uma série de funções administrativas também [...]. A gente tem que orientar monografias, a gente tem que orientar iniciação científica. A gente, quando fala do nosso plano de trabalho, a gente não contabiliza quantas bancas de mestrado, você vai participar, quantas bancas de doutorado, quantos pareceres para uma revista você vai ter que dar naquele semestre. Então, tudo isso fica como um trabalho invisível, que sobrecarrega. A gente sente que cai a qualidade do trabalho, cai a qualidade de vida. Então, é uma situação que os docentes têm passado, de forma muito consistente (D3).

Assim, verificou-se a preocupação dos docentes com a exploração humana no trabalho docente, cada vez mais presente no cotidiano universitário, apresentando-se diminuição na qualidade de vida pela sobrecarga de trabalho, pelo acúmulo de tarefas e pelo produtivismo exagerado.

Analisando as condições de trabalho na universidade, é possível identificar percepções sobre as exigências do trabalho administrativo, dos horários reduzidos por essa atividade, além de ser atribuição não valorizada e que demanda muita dedicação. Deste modo, é possível verificar que os participantes envolvidos nas rotinas administrativas de suas universidades percebem a sobrecarga de trabalho dessa atribuição. A produtividade é representada pela cobrança de órgãos superiores à Universidade como Coordenação de Aperfeiçoamento de Pessoal de Nível Superior (CAPES) e Conselho Nacional de Desenvolvimento Cientifico e Tecnológico (CNPq), por custeamento de pesquisas, publicações de artigos em periódicos avaliados pelo qualis, publicações de livros com inscrições bibliográficas, e, ainda, a atuação na pós-graduação, mesmo quando os docentes estão realizando uma pós-graduação como doutorado ou pós-doutorado. Além de desenvolver certa competição entre os próprios docentes, levando-os ao cansaço, estresse e à frustração (LIMA, 2009). Porém, a própria aceitação destas exigências por produtividade implica na continuidade do processo de exploração do docente (SILVA, 2006).

Com isso, compreende-se que o trabalho docente está à mercê da lógica do mercado, quando se cria sistema de avaliação produtiva, em que a quantidade é valorizada em prejuízo, na maior parte das vezes, da qualidade. Dessa forma, se cria uma cultura que diferencia quem 
é produtivo de quem não se enquadra nesse sistema de produção (LIMA, 2009). Mancebo et al. (2006) contrapõem esse sistema de produção, relatando que boa parte dos trabalhos preza pelo mero produtivismo e ausência de pensamento e de criação.

Outros relatos demonstram sofrimento psíquico, cansaço, insatisfação e pressão causados pela sobrecarga de trabalho.

Ainda não estou completamente certo de que eu estou fazendo o máximo que eu poderia não. Então isso ainda está me angustiando um pouco (D9).

Quando você percebe que tem que produzir, esse tem que produzir não é para você, não é qualidade. Esse olhar te escraviza (D5).

[...] No outro dia tem que acordar cedo, você acorda cansado. Isto é comum. Mas, eu tenho consciência que isso é um mal do excesso de trabalho (D8).

O enfrentamento de inúmeras responsabilidades representa sobrecarga de trabalho, que provoca o esgotamento e, consequentemente, a desmotivação (SILVA, 2006). Essas condições configuram fatores psicossociais do trabalho que podem gerar sobrecargas de trabalho que trazem consequências para a satisfação, saúde e bem-estar dos trabalhadores (MARTINEZ, 2002). De acordo com Dejours (1994), certas condições de trabalho fazem "emergir um sofrimento que pode ser atribuído ao choque entre uma história individual, portadora de projetos, de esperanças e de desejos e uma organização do trabalho que os ignora". Deste modo, a sobrecarga no trabalho dos docentes universitários pode causar consequências irreparáveis, tanto na saúde mental, como no estilo e na qualidade de vida dos docentes.

\section{Tema 7}

\section{$\underline{\text { Realização no trabalho }}$}

Quanto à sensação de satisfação profissional, constataram-se percepções, como realização profissional, nas entrevistas dos docentes universitários, principalmente pelo sentimento de prazer, reconhecimento e oportunidade de capacitação:

Eu me sinto realizada com a profissão porque ela proporciona a possibilidade da capacitação e progressão profissional do conhecimento (D6).

Eu não estou aqui por dinheiro, até porque eu ganhava mais na iniciativa privada, estou aqui por satisfação pessoal (D8).

Me sinto realizado porque eu sempre quis ser professor, e tenho realizado trabalhos e tenho sido reconhecido, acho que isso é uma questão importante (D4). 
Segundo Martinez (2002), o trabalho é um dos elementos da felicidade humana e a felicidade no trabalho é resultado da satisfação plena de necessidades psicossociais, do sentimento de prazer e do sentido de contribuição no exercício da atividade profissional, o que pode explicar a sensação de prazer e realização profissional do docente universitário. Apesar da natureza do trabalho do docente do magistério superior apresentar particularidades já citadas nas outras categorias de análises, como atividades múltiplas no ensino da graduação e pósgraduação, extensão, pesquisa, além de executar atividades administrativas essas características, que o expõem a fatores estressantes, podem repercutir sobre sua saúde física, mental, sobre a qualidade de sua vida e de seu trabalho (CARLOTTO, 2007).

Portanto, trabalhar é estar sujeito a experiências e sentimentos que compõem sofrimento e prazer; realização e frustração. A ambivalência entre prazer e sofrimento faz parte do mundo do trabalho docente (RAUBER; REBOLO, 2011).

A sensação de realização profissional permite aos docentes bom desempenho para concretização dos seus compromissos profissionais e contribue no resultado final do seu trabalho. Deve-se considerar que quando o professor sente-se bem e realizado com o que faz, ele transmite isso aos alunos, elaborando aulas criativas, apresenta-se com mais disposição para trabalhar e também maior dedicação (FERREIRA, 2011).

Além disso, Marqueze e Moreno (2005) relatam que a satisfação do trabalhador com sua atividade reflete em sua qualidade de vida, destacando a importância desse aspecto no ambiente de trabalho e na saúde do trabalhador.

\section{Tema 8:}

\section{Carreira e Qualidade de Vida}

Foi possível identificar que, para os docentes, a carreira universitária pode afetar a qualidade de vida ocorrendo a sensação de pressão e da dedicação excessiva.

Sim, com certeza a carreira do docente universitário pode afetar a qualidade de vida. [...] quanto mais pressão você sente, mais isso vai afetar (D4).

A carreira pode afetar a qualidade de vida sim. Porque a carreira do docente universitário, absorve a pessoa completamente (D5).

Acredito que a minha carreira, ela pode afetar de forma muito consistente a minha qualidade de vida. E a carreira da gente ocupa um espaço muito importante na vida da gente, mas que precisa ter limites para ela, senão, ela toma conta de tudo. [...] porque vou me destacar na minha carreira, mas será que nos próximos 20 anos eu vou conseguir levar a vida assim? É essa a vida que eu quero? (D3). 
A carreira pode afetar tanto positivamente quanto negativamente a qualidade de vida. No meu ponto de vista, o nosso desafio é encontrar um equilíbrio, no trabalho, vida familiar e vida pessoal (D8).

A carreira docente pode afetar a qualidade de vida, tanto positiva quanto negativamente, depende da percepção do docente, bem como das condições de seu trabalho. E para essa categoria, o trabalho assume dimensão essencial para os docentes, sendo uma profissão em que a cultura e o reconhecimento social são preponderantes (KOETZ, 2013). Da mesma forma, vivenciar os momentos de lazer de descanso e o ambiente no trabalho, como um espaço agradável, são importantes, para que haja sentimento de realização. Deve-se considerar, também, que, quando o professor sente-se bem e realizado com o que faz, sentirá mais disposição para fazer seu trabalho e apresentará maior dedicação ao mesmo.

Para Costa (2000), o conforto físico e socioafetivo também são necessários para promover a humanização nas relações de trabalho, para que possa existir um vivenciar saudável, tanto individual, quanto coletivo. A partir disso, torna-se evidente que a busca por apoio, ações de promoção e educação a saúde, repensar as necessidades pessoais e coletivas, limitar as cargas de trabalho e modificar a forma de avaliação do trabalho dos docentes, são mudanças fundamentais para pensar-se na qualidade de vida dos docentes universitários.

\section{CONCLUSÃO}

O estudo foi realizado com intuito de averiguar como a carreira do docente universitário afeta sua qualidade de vida. A partir daí, verificou-se que a definição de qualidade de vida dos docentes não está restrita aos aspectos econômicos, sendo compreendida como conceito subjetivo, que está relacionado à satisfação sobre as condições físicas, psicológicas, afetivas, emocionais, financeiras, saúde, lazer, tempo, obter boas relações familiares, realização com o trabalho e bem-estar.

Apesar de uma visão positiva sobre qualidade de vida, constatou-se que existem aspectos do trabalho docente que interferem diretamente em sua qualidade de vida. Principalmente no que se refere à sobrecarga de trabalho, havendo a necessidade da realização de atividades ocupacionais em seu ambiente doméstico, por causa da demanda e do excesso de atividades, assim privando-os de forma rotineira de suas atividades sociais, atividades de lazer e o tempo com a família, dificultando também a prática de atividades físicas. Com isso, nota-se a vontade dos sujeitos entrevistados de reduzir sua jornada de trabalho, suas atribuições e obrigações para poder dedicar mais tempo à saúde, à família, ao lazer e à realização de atividades físicas. 
Com relação aos aspectos relacionados com a saúde dos docentes, percebe-se a influência direta da sobrecarga de trabalho e, consequentemente, o surgimento de estresse, acarretando dor de cabeça, alterações na visão, depressão, somatização de sintomas, como dor na garganta, ansiedade, cansaço mental, alterações dermatológicas e alterações metabólicas.

Os resultados apresentam ainda reflexões sobre como o desenvolvimento da profissão e o atual sistema educacional de avaliação dos docentes, que estimula um sistema de "ranqueamento" das instituições e prezam pela quantidade de resultados da produção intelectual, como as publicações, e estimulam pouco a criação e a inovação, bem como qualidade do que se produz, acometem a vida do docente, tanto no aspecto pessoal como nas relações interpessoais no trabalho. Essa condição remete aos docentes sensação de frustração e de pressão pela produção, trazendo à tona uma situação próxima à exploração, que afeta as relações no trabalho. A competição pela produtividade estimula desavenças ideológicas, individualismo e abuso de poder entre os pares, isso reflete no ambiente de trabalho de tal forma que surge uma atmosfera hostil e de desafetos.

Apesar dos docentes se depararem com um ambiente de trabalho muitas vezes sem condições adequadas para o desenvolvimento do seu bem-estar, verificou-se que os docentes da UFV demonstraram orgulho, satisfação, sentimento de prazer em serem docentes, uma realização intrínseca explicada pela admiração à profissão.

Nota- se a necessidade da conscientização de que existe sobrecarga de trabalho na carreira dos docentes universitários, pelos gestores responsáveis por desenvolver e manter o sistema educacional atual, modificando-o, alterando seus princípios e, principalmente, a forma de avaliação da produção intelectual, preservando o papel e o bem-estar dos atores que o compõe, estimulando ações para promoção da saúde, lazer e atividade física.

Além disso, é necessário, também, pensar em espaço de apoio aos docentes, guiados por responsável capacitado, especialista em saúde mental, como psicólogos, psiquiatras ou psicanalistas, onde possam expor suas ansiedades, frustrações, angústias e dúvidas. Assim, o professor pode auxiliar o outro em suas dificuldades, construindo-as e desconstruindo-as, e as potencialidades em ser professor, com intuito de melhorar as relações interpessoais no trabalho e o bem-estar docente. Os resultados desse estudo apontam para o fato que existem aspectos da carreira docente que afetam a qualidade de vida dos docentes diminuindo-a. Assim, esperase com este estudo contribuir para a melhoria dos cenários das instituições de ensino superior e atentar para a criação de programas que estimulem a manutenção da QV de seus docentes, revertendo na melhoria e na sustentabilidade das relações, bem como na qualidade do ensino.

Por último fica a admiração por escolherem o desafio de serem educadores, que exige constante formação e dedicação. 


\section{REFERÊNCIAS}

ANDRADE, Alexandro. Ocorrência e controle subjetivo do stress na percepção de bancários ativos e sedentários: a importância do sujeito na relação "atividade física e saúde". 396 f. Tese (Doutorado em Engenharia de Produção) - Centro de Ciências Tecnológicas, Universidade Federal de Santa Catarina, Florianópolis, 2001. Google

BERNHOEFT, Renato. Trabalhar e desfrutar: equilíbrio entre vida pessoal e profissional. São Paulo: Nobel, 1991. Google

BLAIR, Steven N.; APPLEGATE, William B.; DUNN, Andrea L.; ETTINGER, Walter H.; HASKELL, William L.; KING, Abby C.; MORGAN, Timothy M.; SHIH, Joanna H.; SIMONS-MORTON, Denise G. Activity Counseling Trial (ACT): rationale, design, and methods. Medicine Science Sports Exercise, v. 30, n. 7, p. 1097-1106, 1998.

CARLOTTO Mary Sandra; CÂMARA Sheila. Gonçalves. Preditores da síndrome de Burnout em professores. Psicol Esc Educ, v.1, n. 11, p. 101-10, 2007. [Visualizar] Google

CONTAIFER, Tatiana Rodrigues Corrêa; BACHION, Maria Márcia; YOSHIDA, Thaís; SOUZA, Joaquim Tomé. Estresse em professores universitários da área de saúde. Revista Gaúcha de Enfermagem, Porto Alegre, p. 215-25, 2003. [Visualizar] Google

COSTA, Gustavo Pereira. Qualidade de vida no trabalho de docentes da Universidade Estadual do Maranhão. 97 f. Dissertação (Mestrado em Administração) - Universidade Federal de Santa Catarina, Florianópolis, 2000. [Visualizar] Google

DARIDO, Suraya Cristina. Apresentação e análise das principais abordagens da Educação Física escolar. Revista Brasileira de Ciências do Esporte, v. 20, n. 1, p.58-66, 1998 . Google

DEJOURS, Christophe. A carga psíquica do trabalho. São Paulo: Atlas, 1994. Google

DURKHEIM, Émile. A divisão do trabalho social. In: GIANNOTTI, José Arthur (Org.). Durkheim (Col. Os Pensadores). São Paulo: Abril Cultural, p. 3-70. 1978. Google

FERNANDES, Rogério. Ofício de professor: O fim e o começo dos paradigmas. Práticas educativas, culturas escolares, profissão docente. São Paulo: Escrituras, 1998. Google

FERREIRA, Ana. Cássia. Mendes. Satisfação no trabalho de docentes de uma instituição pública de ensino superior: reflexos na qualidade de vida. $126 \mathrm{f}$. Dissertação (Mestrado em Enfermagem) - Universidade Federal de Goiás, Goiânia, 2011. Google

FLECK, Marcelo Pio de Almeida; LOUSADA, Sérgio; XAVIER, Martha; CHACHAMOVICH, Eduardo; VIEIRA, Guilherme; SANTOS, Lyssandra; PINZON, Vanessa. Aplicação da versão em português do instrumento de avaliação de qualidade de vida da Organização Mundial da Saúde (WHOQOL-100). Rev saúde pública, v. 33, n. 2, p. 198-205, 1999. Scrosset Google

FONTANELLA, Bruno José Barcellos; RICAS, Janete; TURATO, Egberto Ribeiro. Amostragem por saturação em pesquisas qualitativas em saúde: contribuições teóricas [Saturation sampling in qualitative health research: theoretical contributions]. Cad saúde pública, v. 24, n. 1, p. 17-27, 2008. [Visualizar] Google 
FOX, Edward. Bases fisiológicas da Educação Física e dos desportos. Rio de Janeiro: Guanabara Koogan, 1991. Google

GARCIA, Átala Lotti; OLIVEIRA, Elizabete Regina Araújo; BARROS, Elizabete Barros. Qualidade de vida de professores do ensino superior na área da saúde: discurso e prática cotidiana. Cogitare Enfermagem, v. 13, n. 1, 2008. Ecrosser Google

HUÉ, Carlos Garcia. Bienestar docente y pensamiento emocional. Revista Fuentes, n. 12, 2012. Google

KOETZ, Lydia; REMPEL, Claudete; PERICO, Eduardo. Qualidade de vida de professores de Instituições de Ensino Superior Comunitárias do Rio Grande do Sul. Ciênc. saúde coletiva, v. 18, n. 4, p. 1019-1028, 2013. Google

LIMA, Maria Fernanda Mendonça; LIMA-FILHO, Dario de Oliveira. Condições de trabalho e saúde do/a professor/a universitário/a.Ciências \& Cognição, v. 14, n. 3, p. 62-82, 2009. [Visualizar] Google

LIPP, Marilda Novaes; MALAGRIS, Lucia Novaes. O Stress Emocional e seu Tratamento.In Bernard Range (Org) . São Paulo: Artes Medicas. 2002. Google

MARQUEZE, Elaine Cristina; DE CASTRO MORENO, Claudia Roberta. Satisfação no trabalho - uma breve revisão. Revista Brasileira de Saúde Ocupacional, v. 30 n. 112, p. 69-79, 2005.

Google

MARTINEZ, Maria Carmen. As relações entre a satisfação com aspectos psicossociais no trabalho e a saúde do trabalhador. 255f. Dissertação (Mestrado em Psicologia) - Universidade de São Paulo, São Paulo, 2002. Google

MASLACH, Christina. Teacher Burnout: A Research Agenda. Understanding and preventing teacher burnout: A sourcebook of international research and practice, p. 295, 1999.

MILES, Matthew; HUBERMAN, Michael. Qualitative data analysis: An expanded sourcebook. Sage, 1994. Google

MINAYO, Maria Cecília de Souza. Pesquisa social: teoria, método e criatividade, 1992.

NAHAS, Markus Vinicius. O conceito de vida ativa: a atividade física como fator de qualidade de vida. Boletim do NuPAF-UFSC, n. 3, p.1, 1995. Google

OLIVEIRA, Amauri Aparecido Bassoli. Metodologias emergentes no ensino da Educação Física. Revista da Educação Física/UEM, v. 8, n. 1, p. 21-27. 1997. Google

PEREIRA, Orcine Aparecida Vieira. Qualidade de vida no trabalho de docentes universitários de uma instituição pública e outra privada do leste de Minas Gerais. $99 f$. Dissertação (Mestrado em Meio Ambiente e Sustentabilidade) - Centro Universitário de Caratinga, Caratinga, 2006. Google

PEREZ, Juan Ramos. Stress no ambiente organizacional: conceitos e tendências. Boletim de Psicologia, São Paulo, p. 89-97, 1992. Google 
PESCATELLO, Linda. Exercising for Health: The Merits of Lifestyle Physical Activity. West Journal Medical, v. 174, n. 2, p. 114-118, 2001. [Visualizar]

PINTO, Samuel Gonçalves. Relações entre família, trabalho e lazer: o caso dos professores da Universidade Federal de Viçosa. 97 f. Dissertação (Mestrado em Economia Doméstica) Universidade Federal de Viçosa, Viçosa, 2008. Google

REBOLO, Fabio; RAUBER, Ana Maria Trindade Rodrigues. Trabalho docente: o mal-estar e os desafios da profissão na conquista do prazer, do bem-estar e da felicidade. IV seminário povos indígenas e sustentabilidade saberes tradicionais e formação acadêmica, 2011.

REIS, Briana Manzan. TRABALHO DOCENTE E QUALIDADE DE VIDA. VII Encontro de Pesquisa em Educação, v. 1, n. 1, p. 37-48, 2013. Google

REQUIXA, Renato. O lazer no Brasil. Editora Brasiliense, 1977. Google

SILVA, Marco. Aurélio Dias; DE MARCHI, Ricardo. Saúde e qualidade de vida no trabalho. São Paulo: Best Seller, 1997. Google

SILVA, Rudney. Características do estilo de vida e da qualidade de vida de professores do ensino superior público em Educação Física. 265f. Tese (Doutorado em Engenharia de Produção) - Universidade de Santa Catarina, Florianópolis, 2006. Google

SILVEIRA, Tereza Cristina Gonçalves Pereira. Desenvolvimento emocional: elemento precursor para o equilíbrio profissional e consequente qualidade de vida. $186 \mathrm{f}$. Dissertação (Mestrado em Educação) - Universidade Católica do Rio Grande do Sul, Porto Alegre, 2006.

SILVERIO, Maria Regina; PATRICIO, Zuleica Maria; BRODBECK, Ingrid May e GROSSEMAN, Suely. O ensino na área da saúde e sua repercussão na qualidade de vida docente. Rev. bras. educ. med. [online], v. 34, n.1, p. 65-73, $2010 . \quad$ crosser Google

SINGER, Paul Israel. Diploma, profissão e estrutura social. Universidade, escola e formação de professores. São Paulo: Brasiliense, 1986. Google

SOUSA, Pollyanna Taiana de Morais; SOUSA, Agna Roberta Rodrigues; PACHECO, Edildete Sene; SOUSA, Giovanna Tainara de Morais. Sedentary behavior among professionals in the family health strategy. REUFPI, v.6, n. 1, 2017. Google

TAFFAREL, Celi Zulke. Formação profissional inicial e continuada e produção de conhecimento científicos na área de educação física e esportes no nordeste do Brasil: um estudo a partir da UFPE. In: Congresso Brasileiro de Ciências do Esporte, 10, Anais [...]. 1997. Google

TARDIF, Maurice; RAYMOND, Danielle. Saberes, tempo e aprendizagem do trabalho no magistério. Educ. Soc. Campinas, v. 21, n. 73, 2000. Zcrossret Google

ULRICH, Elizabeth. Percepções de professores universitários sobre as relações interprofissionais que levam ao estresse. $147 \mathrm{f}$. Dissertação (Mestrado em Psicologia) Universidade Federal de Santa Catarina, Florianópolis, 2005. [Visualizar] Google 
ZAMAI, Carlos Aparecido; BANKOFF, Antonia Dalla Pria; PERES, Cláudia Maria; GRAZIA, Renata Cristina. Análise do perfil da saúde de servidores da universidade estadual de campinas.

Revista Saúde e Meio Ambiente - RESMA, v. 6, n.1, 2018. [Visualizar] Google 